\title{
Hyperaccumulator and Potential Hyperaccumulator from Two Climate-Ecology Regions Affect Photosynthetic Characteristics of Eggplant (Solanum melongena L.) under Cadmium Stress by Intercropping
}

\author{
Yi Tang ${ }^{1, a}$, Huanxiu $\mathrm{Li}^{1, \mathrm{~b}^{*}}$ \\ ${ }^{1}$ Institute of Pomology and Olericulture, Sichuan Agricultural University, Chengdu, Sichuan, China \\ atangyisunguochao@sina.com, bhxli62@163.com \\ ${ }^{*}$ Corresponding author
}

Keywords: Intercropping; Photosynthetic characteristics; Eggplant (Solanum melongena L.); Cadmium stress

Abstract. A pot experiment was conducted to study the effects of intercropping with Solanum photeinocarpum and Solanum nigrum from two climate-ecology regions (Ya'an campus and Chengdu campus) on photosynthetic characteristics of eggplant under cadmium (Cd) stress. Five treatments were used in the experiment: 4 eggplant seedlings were monocultured in one pot (CK), 3 eggplant seedlings intercropping with $1 \mathrm{~S}$. nigrum seedling from Chengdu(henceforth LC), 3 eggplant seedlings intercropping with 1 S. nigrum seedling from Ya'an (henceforth LY), 3 eggplant seedlings intercropping with $1 \mathrm{~S}$. photeinocarpum seedling from Chengdu(henceforth SC), 3 eggplant seedlings intercropping with 1 S. photeinocarpum seedling from Ya'an (henceforth SY). The results showed that intercropping enhanced net photosynthetic rate $(\mathrm{Pn})$, transpiration rate $(\mathrm{Tr})$ and stomatal conductance (Gs) of eggplant significantly. Intercropping with S. photeinocarpum was better than with S. nigrum. As to the same plant, the Pn, Tr and Gs of eggplant intercropping with the one from Ya'an campus (the Mountain-Central Subtropical-Cold Zone of the Western Sichuan Basin) was higher than with the one from Chengdu campus (the Central Subtropical-Long-Spring and Summer-Drought Zone). There was little difference from the result of $\mathrm{Ci}$, compared with $\mathrm{CK}$, after intercropping with $S$. photeinocarpum and $S$. nigrum, Ci of eggplant also increased, however, treatments of different climate-ecology regions were not significant. Therefore, intercropping with S. photeinocarpum and S. nigrum could use to enhance the photosynthetic ability of eggplant, which would help to improve the adaptability of eggplant.

\section{Introduction}

Eggplant (Solanum melongena L.) is one of the most commonly eaten vegetables in the world [1]. Under cadmium stress, leaf area and biomass of eggplant are decreased [2]. Some studies show that intercropping can enhance plant productivity by promoting the efficiency of light, water, and fertilizer use [3-4]. In intercropping system, while roots of two plants contact with each other, rhizosphere talk would occur to promote or inhibit plant growth [5]. Recent studies have reported that hyperaccumulators intercropped with ordinary plants can reduce the heavy metal accumulation and enhance crop yields in the latter, while the heavy metal uptake of the former was enhanced [6-8]. However, other studies indicate that hyperaccumulator intercropping with ordinary plants dose not affect the growth and heavy metal accumulation in two types of plants [9]. Thus, the impact of intercropping varies according to crop combination, and it needs to be examined on a case-by-case basis.

In this study, we used two climate-ecology regions (Chengdu City and Ya'an City) of S. nigrum (cadmium hyperaccumulator [10]) and S. photeinocarpum (potential Cd-hyperaccumulator [11]) respectively to intercrop with eggplant seedlings, to screen the effects of intercropping on photosynthetic characteristics of eggplant under Cd stress. 


\section{Materials and Methods}

Materials. Experiments were conducted at Sichuan Agricultural University, Chengdu, China. The seeds of eggplant were harvested in 2014 and provided by Zhongdu Seed Company (Chengdu, China). Two plants of $S$. nigrum and $S$. photeinocarpum were collected from Chengdu campus farm of Sichuan Agricultural University $\left(30^{\circ} 42^{\prime} \mathrm{N}, 103^{\circ} 51^{\prime} \mathrm{E}\right)$ and Ya'an campus farm of Sichuan Agricultural University $\left(29^{\circ} 59^{\prime} \mathrm{N}, 102^{\circ} 59^{\prime} \mathrm{E}\right)$ in July, 2014. Matured seeds were collected from the plants, air-dried and stored at $4^{\circ} \mathrm{C}$. Chengdu campus and Ya'an campus are located within two climate-ecology regions of the Western Sichuan Basin: the Central Subtropical-Long-Spring and Summer-Drought Zone, and the Mountain-Central Subtropical-Cold Zone of the Western Sichuan Basin, respectively [12]. All chemicals used in experiments were of analytical grade.

Experimental Design. The soil samples were air-dried and passed through a 5-mm mesh in July 2015 , and then $3.0 \mathrm{~kg}$ of soil was weighed into each polyethylene pot ( $15 \mathrm{~cm}$ tall, $18 \mathrm{~cm}$ diameter). Cd was added to make a final soil Cd concentration of $10 \mathrm{mg} \cdot \mathrm{kg}^{-1}$ with a saturated heavy metal solution in the form of $\mathrm{CdCl}_{2} \cdot 2.5 \mathrm{H}_{2} \mathrm{O}$. The soils were mixed immediately and again after 4 weeks, during this period soil moisture was kept at $80 \%$. Seeds were sterilized in 5\% sodium hypochlorite solution for 5 min, rinsed in distilled water five times, and were placed on 9-cm-diameter Petri dishes with three layers of filter paper moistened with distilled water and germinated at $25^{\circ} \mathrm{C}$ in darkness. Seeds were considered germinated when the seed coat was broken and a radicle was visible. After germination, seeds were planted in seedling tray filled with nursery substrate. When the third leaf expanded, uniform seedlings were transplanted to polyethylene pots which were prepared before.

The intercropping treatments were conducted as follow: 4 uniform-sized eggplant seedlings were transplanted into one pot for monoculture $(\mathrm{CK}), 3$ eggplant seedlings intercropping with $1 \mathrm{~S}$. nigrum seedling from Chengdu(henceforth LC), 3 eggplant seedlings intercropping with $1 S$. nigrum seedling from Ya'an (henceforth LY), 3 eggplant seedlings intercropping with 1 S. photeinocarpum seedling from Chengdu(henceforth SC), 3 eggplant seedlings intercropping with $1 S$. photeinocarpum seedling from Ya'an (henceforth SY).

For each treatment with 3 replicates, and the pots placed completely random. The distance between pots was $15 \mathrm{~cm}$, and the pot position exchanged aperiodically to weaken the impact of the marginal effects. The soil moisture content was maintained at $80 \%$ of field capacity until the plants were harvested. 30 days after intercropping, the photosynthesis of each plant was determined by using LI-6400 portable photosynthesis meter (LI-COR Inc., USA). The photosynthetic parameters of the photosynthesis meter were manual control $\mathrm{CO}_{2}$ concentration $400 \mu \mathrm{mol} \cdot \mathrm{CO}_{2} \mathrm{~mol}^{-1}$, temperature $25^{\circ} \mathrm{C}$, light intensity $1200 \mu \mathrm{mol} \mathrm{m} \mathrm{m}^{-2} \cdot \mathrm{s}^{-1}$. The determination of photosynthetic parameters were net photosynthetic rate $(\mathrm{Pn})$, transpiration rate $(\mathrm{Tr})$, stomatal conductance $(\mathrm{Gs})$ and $\mathrm{CO}_{2}$ concentration of intercellular $(\mathrm{Ci})$, and each treatment was repeated three times.

Statistic analyses. Statistical analyses were performed using SPSS 13.0 statistical software (IBM, Chicago, IL, USA). Data were analyzed by one-way ANOVA with least significant difference (LSD) at a $5 \%$ confidence level.

\section{Results and Discussion}

Net Photosynthetic Rate (Pn). Compared with CK, intercropping enhanced Pn of eggplant under Cd stress significantly. The Pn of eggplant was ranked as: SY > SC > LY> LC> CK. SY, SC and LY enhanced Pn of eggplant by $115.71 \%(p<0.05), 49.62 \%(p<0.05)$ and $45.20 \%(p<0.05)$ respectively, and LC increased by $15.25 \%$ ( $p>0.05$ ) compared with CK (Fig. 1). In this study, it was illustrated that intercropping can alleviate the $\mathrm{Cd}$ stress and improving photosynthetic capacity of eggplant seedlings, and intercropping with S. photeinocarpum was better than with S. nigrum. As to the same plant, the Pn of eggplant intercropping with the one from Ya'an campus (the Mountain-Central Subtropical-Cold Zone of the Western Sichuan Basin) was higher than with the one from Chengdu campus (the Central Subtropical-Long-Spring and Summer-Drought Zone). 
Transpiration Rate (Tr). Compared with CK, intercropping increased $\mathrm{Tr}$ of eggplant under $\mathrm{Cd}$ stress significantly. The Pn of eggplant was ranked as: SY > SC > LY> LC > CK. SY, SC and LY enhanced Pn of eggplant by $126.96 \%(p<0.05), 50.62 \%(p<0.05)$ and $79.16 \%(p<0.05)$ respectively, and LC increased by $26.23 \%$ ( $p>0.05$ ) compared with CK (Fig. 2). The trend of Tr was consistent with Pn.

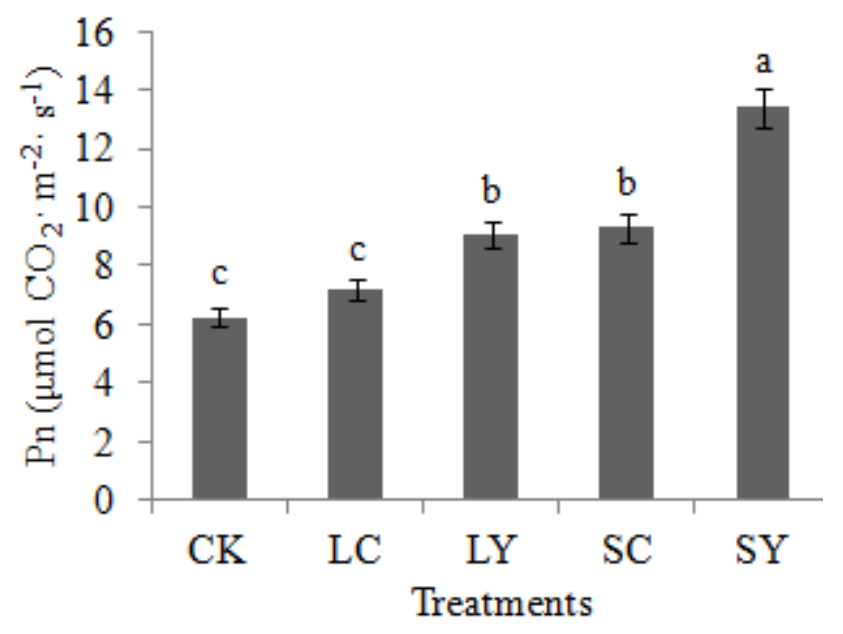

Fig. 1 Pn of S. nigrum and S. photeinocarpum intercrop with eggplant

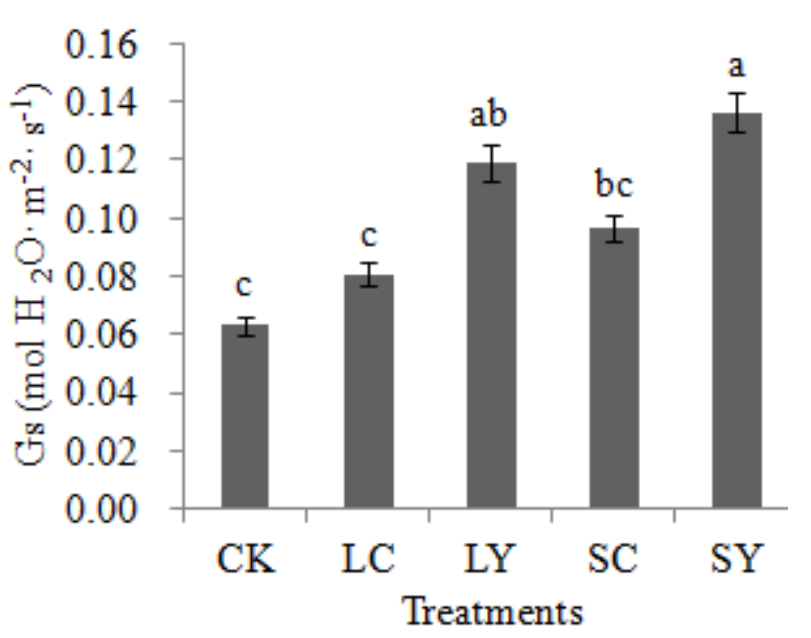

Fig. 3 Gs of S. nigrum and S. photeinocarpum intercrop with eggplant

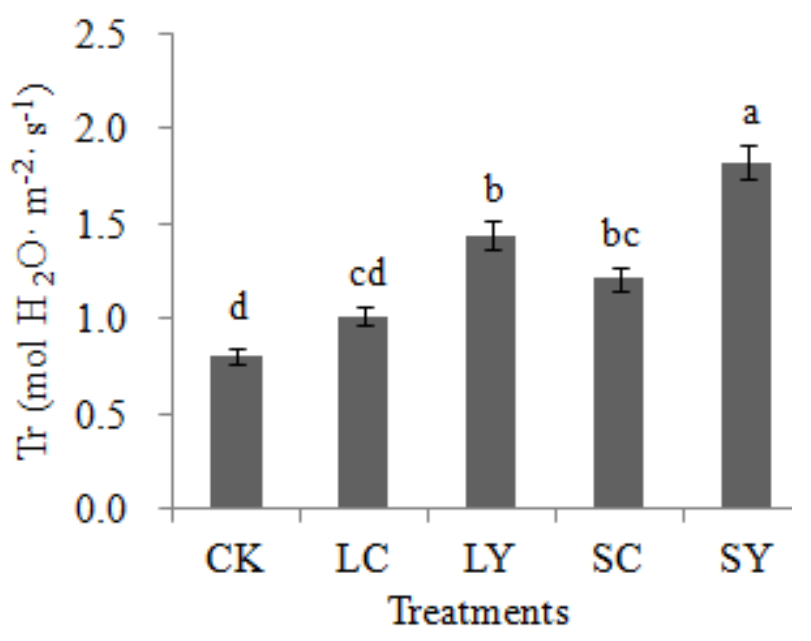

Fig. 2 Tr of S. nigrum and S. photeinocarpum intercrop with eggplant

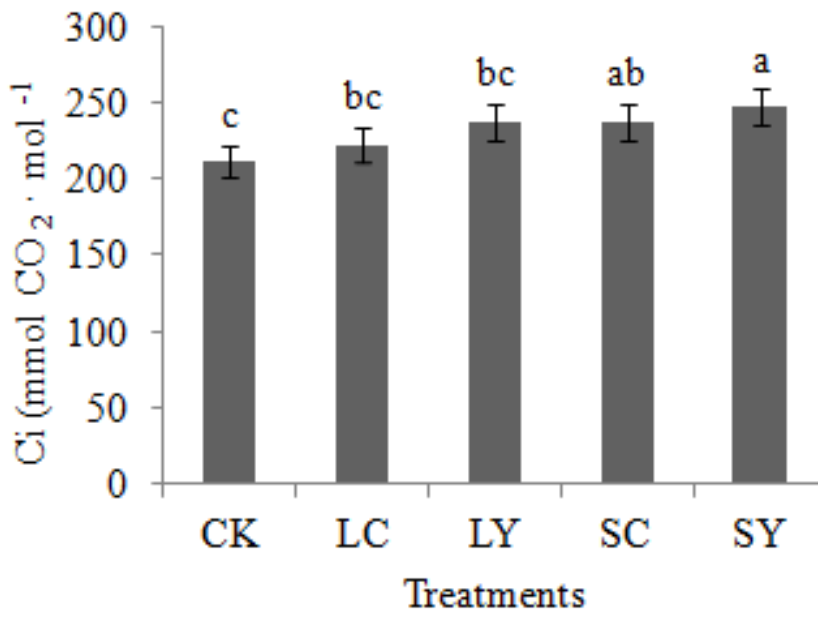

Fig. 4 Ci of S. nigrum and S. photeinocarpum intercrop with eggplant

Stomatal Conductance (Gs). After intercropping with S. photeinocarpum and S. nigrum from two climate-ecology regions (Ya'an campus and Chengdu campus), Gs of eggplant increased (Fig. 3), which was consistent with Pn and Tr. The Gs of eggplant was ranked as: SY $>\mathrm{SC}>\mathrm{LY}>\mathrm{LC}>\mathrm{CK}$. SY, SC and LY enhanced Gs of eggplant by $115.02 \%(p<0.05), 52.66 \%(p<0.05)$ and $88.08 \%(p<0.05)$ respectively, and LC increased by $27.11 \%(p>0.05)$ compared with CK. 
CO2 Concentration of Intercellular (Ci). Compared with CK, after intercropping with $S$. photeinocarpum and $S$. nigrum, $\mathrm{Ci}$ of eggplant increased (Fig. 4). Treatments of different climate-ecology regions were not significant. The $\mathrm{Ci}$ of eggplant reached the highest when intercropping with S. photeinocarpum from the Mountain-Central Subtropical-Cold Zone of the Western Sichuan Basin.

\section{Conclusions}

Intercropping can alleviate the $\mathrm{Cd}$ stress on photosynthetic organ damage and improving photosynthetic capacity of eggplant seedlings. Intercropping with S. photeinocarpum was better than with S. nigrum. As to the same plant, the Pn, Tr and Gs of eggplant intercropping with the one from Ya'an campus (the Mountain-Central Subtropical-Cold Zone of the Western Sichuan Basin) was higher than with the one from Chengdu campus (the Central Subtropical-Long-Spring and Summer-Drought Zone). There was little difference from the result of Ci, compared with CK, after intercropping with $S$. photeinocarpum and S. nigrum, $\mathrm{Ci}$ of eggplant also increased, however, treatments of different climate-ecology regions were not significant. Therefore, intercropping with $S$. photeinocarpum and $S$. nigrum could use to enhance the photosynthetic ability of eggplant, which would help to improve the adaptability of eggplant.

\section{Acknowledgements}

This work was financially supported by the Sichuan Agricultural University "Shuang-Zhi Plan" Foundation, Sichuan Provincial Department of Education Foundation (15ZA0011).

\section{References}

[1] S.Y. Ju, J. Wang and L.B. Shen: Chinese Journal of Ecology Vol. 34 (2015), p. 2181-2186 (In Chinese)

[2] H.J. Jiao, M.F. Niu and S.H. Wei: Asian Journal of Ecotoxicology Vol. 8 (2013), p. 413-418 (In Chinese)

[3] Y.Y. Zhu, H.R. Chen and J.H. Fan: Nature Vol. 406 (2000), p. 707-716.

[4] C.Y. Li, X.H. He and S.S. Zhu: PLoS ONE Vol. 4 (2009), p. e8049.

[5] C.J. Li, W. Ma, and F.S. Zhang: Plant Nutrition and Fertilizer Science Vol. 14 (2008), p. 178-183.

[6] J.X. Wang, Y.Q. Zu and Y. Li: Journal of Agro-Environment Science Vol. 30 (2011), p. 2168-2173.

[7] C.A. Jiang, Q.T.Wu and S.H.Wu : China Environmental Science Vol. 29 (2009), p. 985-990.

[8] X.M. Liu, Q.T.Wu and M.K.Banks: Int J Phytoremediat Vol. 7 (2005), p. 43-53.

[9] B. Yang, W.S. Shu and Z.H.Ye: Chemosphere Vol. 52 (2003), p.1593-1600.

[10]S.H. Wei, Q.X. Zhou and X. Wang: Chinese Science Bulletin Vol. 50 (2005), p. 33-38.

[11]X.F. Zhang, H.P. Xia and Z.A Li: Journal of Hazardous Materials Vol. 189 (2011), p. 414-419.

[12]X.M. Zhu., W.Y. Yang and J.R.Shao: Seed Vol. 23 (2004), p. 3-6, 37. 